\title{
A Fast and Economical Method for Producing of Self-wipe Twin-screw Extruder Modules
}

\author{
M.H.N. Famili and S. Moradi* \\ Polymer Engineering Group, Chemical Engineering Department, Tarbiat Modarres University, Tehran, Iran
}

\begin{abstract}
After the extrusion process the remaining of polymers in the extruders cause some problems like degradation and impurity in process, therefore after each batch the extruder should be cleaned. Using self-wipe twin-screw extruder is a method, to solve this problem. Production of self-wipe screw modules is very difficult, time consuming and is not economical. In this research, we have presented a novel, quick and economical method for producing self-wipe modules with desirable profiles.
\end{abstract}

Keywords: Twin-screw extruder, self-wipe, intermeshing co-rotating screws.

\section{INTRODUCTION}

Twin-screw extrusion is extensively used for mixing, compounding, or reacting polymeric materials. Recently many researchers are trying to do some modification in polymers for specific purpose [1-3]. Reactive extrusion, reactive blending and polymer reinforcement are some of the new topics in research that are more dependent on twin-screw extruder type and configuration. The flexibility of twin-screw extrusion equipment allows this operation to be designed specifically for the formulation being processed. For a specific reaction, the residence time distribution in twin-screw extruder is less than the batch systems. Therefore, this accounts for a decrease of polymer degradation, giving better product than the batch systems. Good residence time distribution, good mixing and high capability of heat and mass transfer in twin-screw extruders led us to use this apparatus [3-6].

In twin-screw extruder, the screws may be co-rotating or counter-rotating, intermeshing or non-intermeshing, conjugated or non-conjugated. In addition, the configurations of the screws themselves may be varied by using forward conveying elements, reverse conveying elements, kneading blocks or other designs in order to achieve particular mixing characteristics [4, 7-9]. Construction features of the twin-screw extruders are shown in the Table 1.

\section{Screw geometry}

The fundamental difference between single and twinscrew is the type of their flow pattern. The velocity profile in the twin-screw extruders is more complex than single screw extruders, thus the theoretical relations of these extruders are not improved like as single screw extruders. Fig. (1) shows the path of the particle in the single screw extruder, non-intermeshing counter-rotating twin-screw extruder and inter-meshing co-rotating twin-screw extruder [9-12].

*Address correspondence to this author at the Polymer Engineering Group, Chemical Engineering Department, Tarbiat Modarres University, Tehran, Iran; E-mail: smoradi@ modares.ac.ir

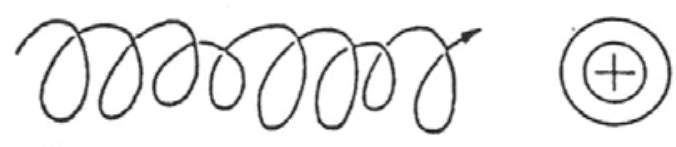

(a) Particle path in the single screw extruder.

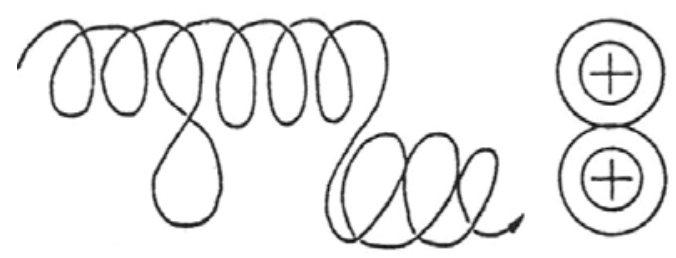

(b) Particle path in the non-intermeshing twin-screw extruder.

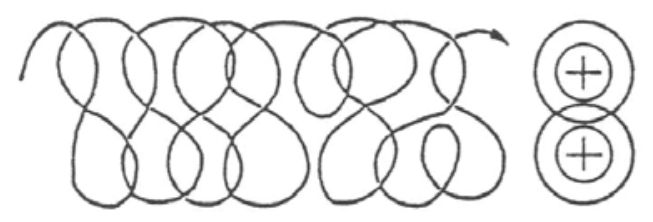

(c) Particle path in the intermeshing twin-screw extruder.

Fig. (1). Comparison of the Particle path between (a) single screw extruder, (b) non intermeshing counter-rotating twin-screw extruder and (c) inter-meshing co-rotating twin-screw extruder.

The screw geometry defined by its application of twinscrew extruders was designed in modular section form. Usually, the screws and the barrels have modular form, thus changing the arrangement of the screw modules on the main shaft make prove easy. Modular design of the screw facilitates the change in the screw configuration for proper application. Also fabricating the screws in modular form may save the time and expense $[7,12,13]$.

In co-rotating twin-screw extruders, self wiping action is achieved by this procedure: one crest edge of the screw wipes the flanks of the other screw with a tangentially oriented, constant relative velocity. There is a higher relative velocity in this arrangement, and hence there is a sufficiently high shear velocity available to wipe the boundary layers, thus a more efficient and uniform self-cleaning action is achieved [11, 1316]. Wiping action of twin-screw extruders is shown in Fig. 
Table 1. Construction Features of Twin-screw Extruders

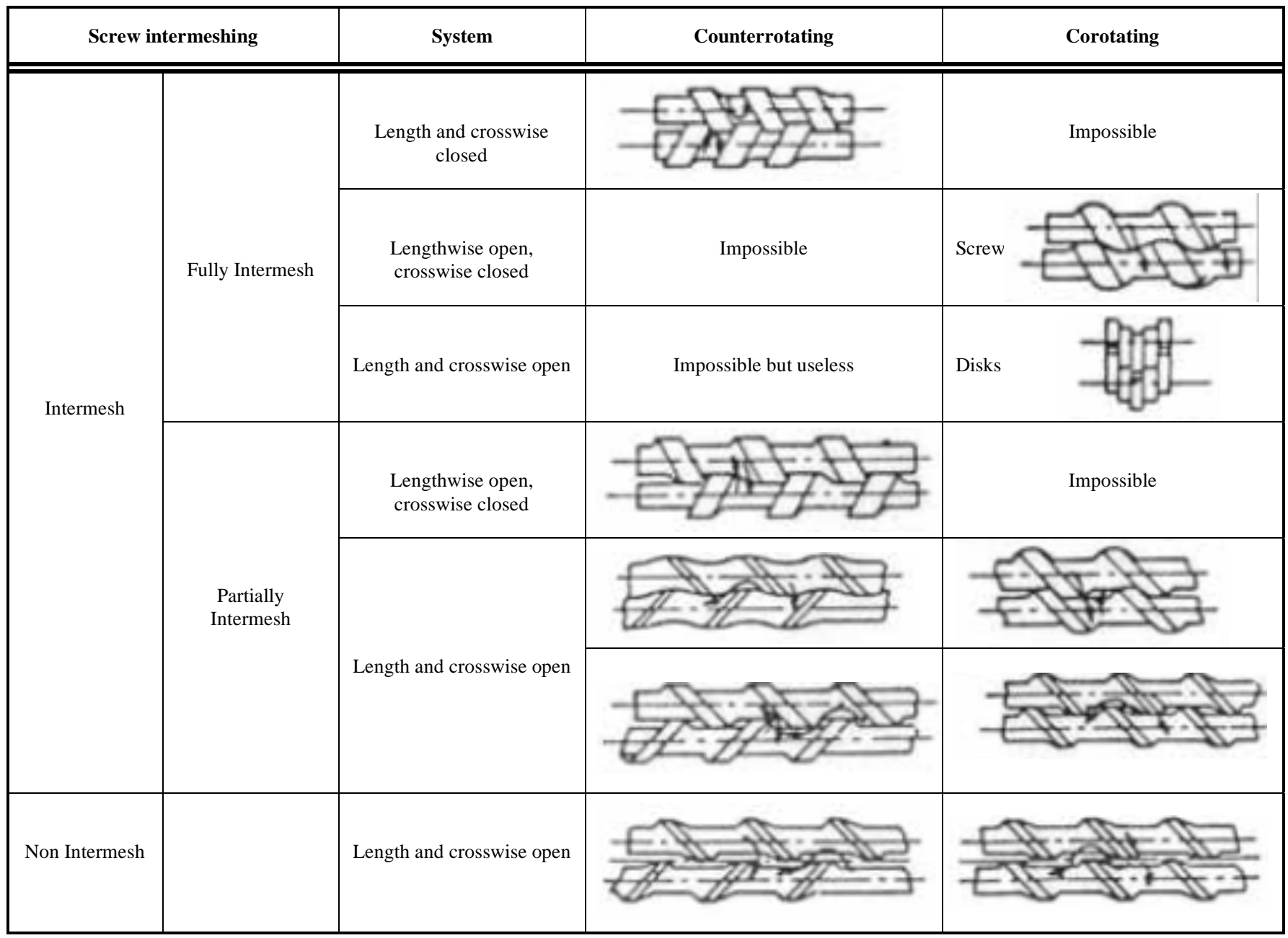

(2). Fabrication of counter rotating self-wipe screw is not feasible.

\section{EXPERIMENTAL}

\section{Fabrications of Self-Wipe Screws}

Some of the screws pattern quite similar to the selfwipe pattern can be prepared with special screw production machines. The type and size of these screws is limited by the producing machine because the pattern of the self-wipe

\begin{tabular}{|l|l|}
\hline \multicolumn{3}{|c|}{ Twin-screw extruder } \\
\hline \multicolumn{2}{|c|}{ Co-rotating }
\end{tabular}

Fig. (2). Wiping action in twin-screw extruders [11]. screw is a unique pattern and these machines can produce only some screws with pitches that are not self-wipe $[8,11]$. We have prepared some of these screws with the mentioned machine (Fig. 3). These screws are fully intermesh but not self-wipe.

Creating a special profile on the flank of screws that when they arranged in twin form will be fully intermesh and one crest edge of the screw wipes the flanks of the other screw and vice versa, is the most important point that should be considered in the fabrication of the self-wipe screws $[12,15]$. It can be done only by creating a sinusoidal profile on the flank of the screws as shown in Fig. (4), [14].

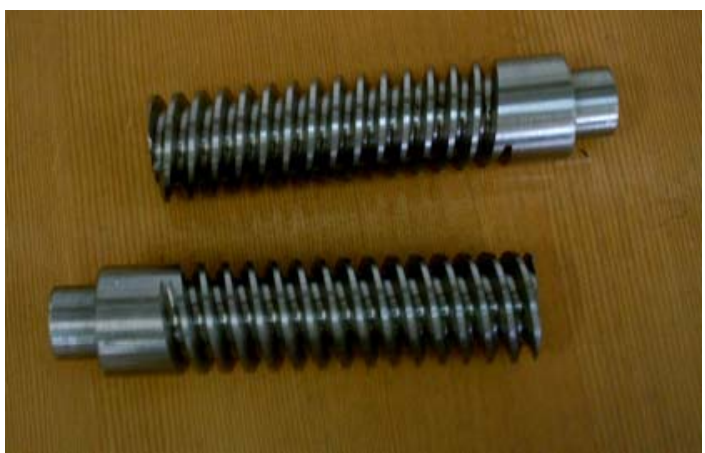

Fig. (3). The sample of screws was prepared with special screw production machine. 


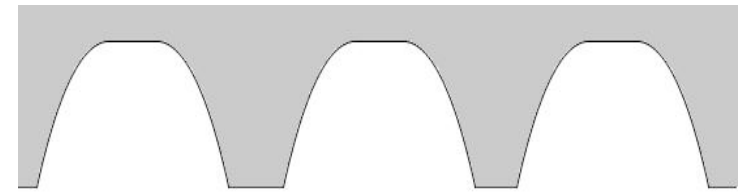

Fig. (4). Sinusoidal profile on the flank of the screw for fabrication of self-wipe screws (screw pitch $20 \mathrm{~mm}$ ).

The main problem in the fabrication of these screws is that the creating of this profile on the flank of the screw by manual lathe machines or CNC lathe machines is not possible. The lathe machines can create sectors with certain $\mathrm{R}$ on the flank of the screws $[13,16]$. Typical twin screws produced by lathe machine are shown in Fig. (5). The flank of these screws is formed of several R.

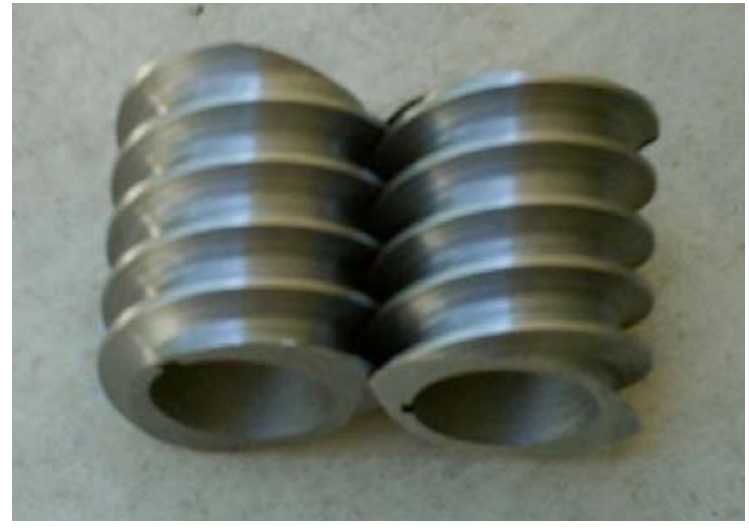

Fig. (5). Screws prepared by lathe machine by using of mould

For flank profile modification, at first we prepared an iron mould with sinusoidal profile by CNC wire cut machine. The prepared mould is shown in Fig. (6). Then by using this mould, we controlled the screw flank profile during the lathing action. By successive controls and doing some modification in the screw at the end, we prepared a screw with a profile close to the self-wipe profile. This screw is not self-wipe but very similar to the self-wipe screw.

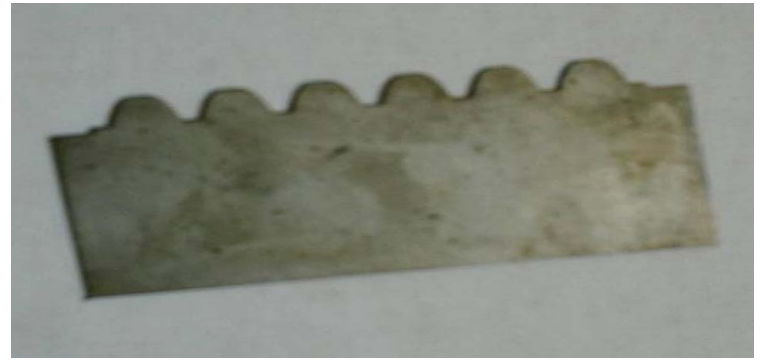

Fig. (6). The prepared mould by $\mathrm{CNC}$ wire cut machine for controlling of the screw flank profile.

Above methods are very difficult, expensive and time consuming. We have presented a novel, quick and Economical method for producing self-wipe modules with desirable profiles. In this method, we prepare the self-wipe screws by using of a common lathe machine with aid of a special cutting tool. At first we prepared a cutting tool from HSS (Fig. 7a), and then created the sinusoidal profile as Fig. (4) by CNC wire cut machine on HSS cutting tool (Fig. 7b). For preventing of body cutting tool interlock with shaft during the lathing, the lateral section of the cutting tool head was removed (Fig. 7c). As regards the

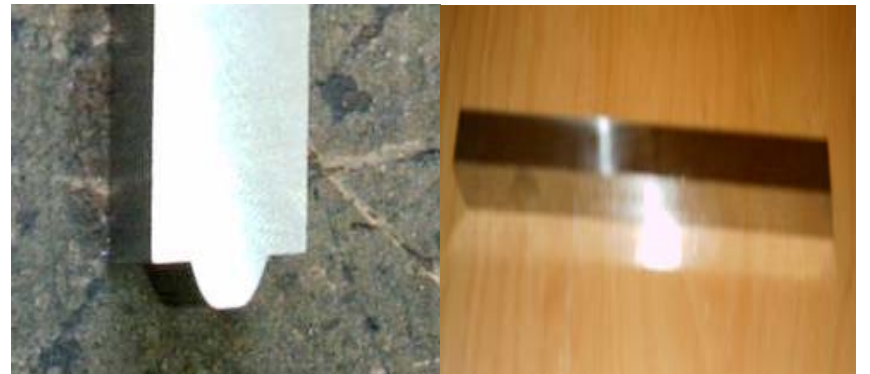

(a)

(b)

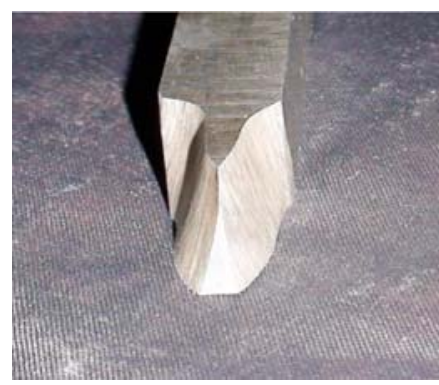

(c)

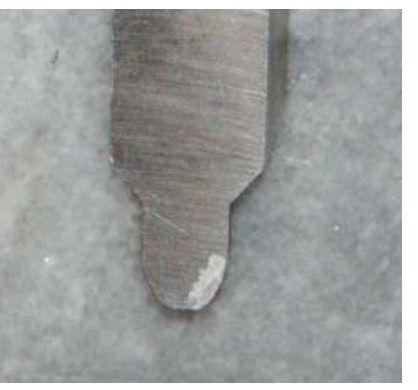

(d)
Fig. (7). (a) HSS Cutting tool lathe for creating the sinusoidal profile of screw. (b) The sinusoidal profile created on the cutting tool lathe by CNC wire cut machine. (c) The Cutting tool lathe shaped when lateral section of it is removed. (d) The back view of the cutting tool lathe when its additional part is removed.

head of this cutting tool lathe, for preparation of a screw, the head of the cutting tool should pass in a helical way on shaft. When the cutting tool is passed on this path, the back of cutting tool head interlocks with the flank of the screw. This problem should be solved with respect to the angle and direction of shaft torsion. In this research, the angle is $17.5^{\circ}$ and screw is right handed. For solving this problem, we removed the left side section of the head of cutting tool lathe, that interlocked with the flank of the screw, by $17.5^{\circ}$ angle with respect to the head section (Fig. 7d). The prepared screws with this method are fully intermeshed and self-wipe. One sample of these screws is shown in Fig. (8). The needed time for preparing of one meter of these modules are about five hours. The modules arranged and fixed on the main shaft to make the screw shaft.

\section{RESULT AND DISCUSSION}

Fabrication of self-wipe modules by using of common and CNC lathe machine is not possible $[8,11]$. The prepared screw by these machines may be improved with burnishing to make them similar to the self-wipe profile, but they can not act as self-wipe modules. This work is very time consuming and expensive with low accuracy. By preparing of cutting tool lathe with the mentioned method in this paper, fabricating of self-wipe screw modules with high accuracy and very low expense is facilitated. Also by applying of this method, fabricating of suitable self-wipe modules by using of a common lathe machine is feasible. The most important advantages of this method is high accuracy, low expense, simplicity and rapidity of the method. The maximum wiping efficiency of the modules prepared with conventional method is about $70 \%$ of prepared self-wipe modules with this new method. The time is 


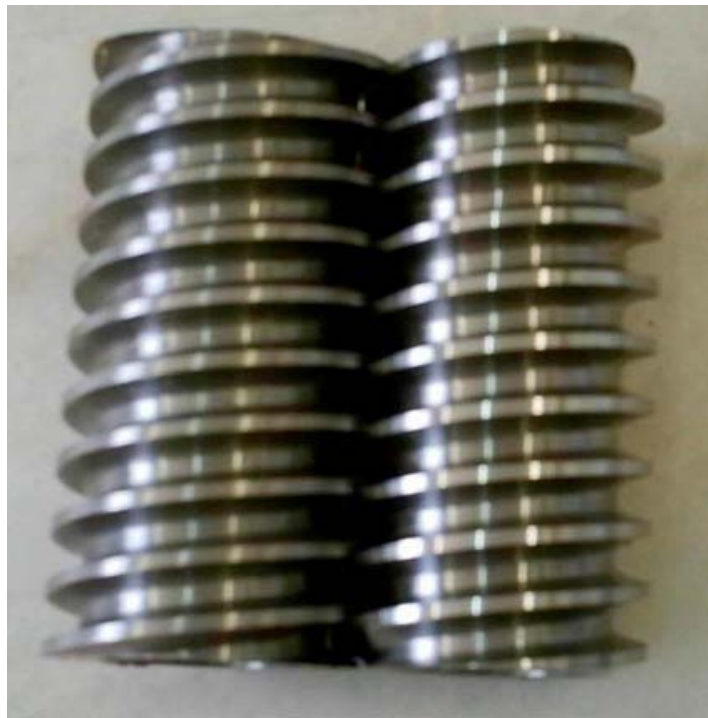

Fig. (8). The final modules of the self-wipe screw prepared with Lathe machine by using special cutting tool shape.

needed for preparing of self-wipe modules with this new method is about $10 \%$ of the conventional method.

\section{REFERENCES}

[1] J.A. Colbert, The Extrusion, Measurement and Control of Medical Tubing, Davis Standard Ltd, Luton, UK, March 1996.

[2] R.J. Castillo, How Do You Extrude 10 Layer Film Sheeting on a 5 Layer Die, Polymers, Laminations \& Coatings Conference, San Diego, CA, 2001, pp. 115.

[3] J. Dooley, Viscoelastic Flow Effects in Multilayer Polymer Coextrusion, Ph.D. Thesis, Eindhoven University of technology, Eindhoven, ON, Netherlands, 2002.
[4] D.G. Baird, D.I. Collias, Polymer processing principles and design, Butterworth-Heinemann Press, USA, 1995.

[5] S.C. Garge, M.D. Wetzel and B.A. Ogunnaike, "Quantification of the melting process in a co-rotating twin-screw extruder: A hybrid modeling approach", Polymer Engineering \& Science, Vol. 47(7), pp. 1040-1051, May 2007.

[6] Y. Wang, "Compounding in Co-rotating Twin-screw Extruders", Rapra Review Report, Vol. 10, No. 8, Report 116, 2000.

[7] J.L. White, Twin-screw Extrusion, Hanser/Gurdner Publications, New York, 1991.

[8] W. Szydlowski, K. Min, M.H. Kim and J.L. White, "Technology and Analysis of Flow", Advances in Polymer Technology, Vol. 7, pp. 177, 1987.

[9] Y. Wang and J.L. White, "Non-Newtonian Flow Modelling in the Screw Regions of an Intermeshing Corotating Twin-screw Extruder", Journal of Non-Newtonian Fluid Mechanics, Vol. 32, pp. 19, 1989.

[10] A. Kiani, J.E. Curry and P.G. Anderson, "Flow analysis of twinscrew extruders pressure and drag capability of various twin-screw elements", SPE ANTEC Technical Papers, Vol. 44, pp. 48-54, April 1998.

[11] Y. Xie, D. Bigio, P. Andersen and J. Cheng, Imaging and Image Analysis Applications For Plastics, Behnam Pourdeyhimi, Society of Plastics Engineers press, Chap 5, 1999.

[12] A. Rom-Rogineski and C.J.B. Dobbin, "A comparative study of the use of high intensity dispersive mixers and co-rotating twin-screw extruders in the manufacture of high quality color concentrates", SPE ANTEC Technical Papers, Vol. 44, pp. 189-198, April 1998.

[13] T. Ishikawa, S. Kihara and K. Funatsu, "3-D non-isothermal flow field analysis and mixing performance evaluation of kneading blocks in a co-rotating twin-screw extruder", Polymer Engineering Science, Vol. 41, pp. 189-849, 2001.

[14] V.L. Bravo, A.N. Hrymak and J.D Wright, "Numerical simulation of pressure and velocity profiles in mixing elements of a co-rotating twin-screw extruder", Polymer Engineering Science, Vol. 40, pp. $525-541,2000$

[15] A. Lawal, S. Railkar and D. Kalyon, "3-D analysis of fully flighted screws of co-rotating twin-screw extruders", SPE ANTEC Technical Papers, Vol. 45, pp. 317-322, 1999.

[16] F.R. Burbank and S.M. Jackson, "New Twin-screw Element Design for Elastomer Compounding", SPE ANTEC Technical Papers, Vol. 57, pp. 225-230, 1999.

(c) Famili and Moradi; Licensee Bentham Open.

This is an open access article licensed under the terms of the Creative Commons Attribution Non-Commercial License (http://creativecommons.org/licenses/bync/3.0/), which permits unrestricted, non-commercial use, distribution and reproduction in any medium, provided the work is properly cited. 